\title{
Fragmentación entre ciencia y humanismo en la universidad contemporánea*
}

\author{
María Adelaida López Alzate
}

\begin{abstract}
Resumen
Recibido: 15 de mayo 2014

A través de este ensayo se propone analizar la fragmentación Evaluado: 17 de julio de 2014 que se presenta en la universidad moderna entre la ciencia y el Aceptado: 3 de agosto de 2014 humanismo, teniendo en cuenta las consecuencias de la modernidad en la esfera del saber y del conocimiento. Finalmente, se pretende no únicamente describir dicha fragmentación, sino establecer algunas propuestas para dar vías de salida en el planteamiento de nuevas perspectivas en la educación superior.

Se comenzará enunciando el problema de la fragmentación entre ciencia y humanismo como si se tratase de dos culturas; seguidamente se revisa la incursión de un elemento más representado en las ciencias sociales, dando como resultado a tres culturas. Los aspectos relacionados con el conocimiento, el modelo de ciencia y el concepto de razón se revisan para continuar con el análisis proponiendo que la fragmentación entre ciencia y humanismo es otra manifestación de la llamada modernidad líquida, propuesta sociológica referida por Bauman (2002). Finalmente, para superar o bien minimizar la fragmentación dentro de la universidad, se propone a la transdisciplinariedad y el diálogo de saberes como formas de construcción de nuevas epistemes,
\end{abstract}

El siguiente documento fue realizado en el marco del proyecto "Articulación entre ciencia y humanismo, nuevas perspectivas en la Educación Superior" propuesto en 2011, en convocatoria interna de la Universidad Santo Tomás, por parte del grupo de investigación Pludehuco, categoría D en Colciencias. Investigador director. Diego Germán Pérez. A pesar de que el proyecto no contó con la financiación de la universidad, el equipo siguió trabajando en la investigación, con la metodología de seminario alemán. El documento es un artículo de reflexión por cuanto propone una perspectiva analítica, interpretativa y crítica sobre la relación entre ciencia y humanismo en la universidad. Cómo citar este artículo: López Alzate, M.A. (2014). Fragmentación entre ciencia y humanismo en la universidad contemporánea. Hallazgos, 11(22), 329-357.

** Docente de la Universidad Santo Tomás, Unidad de Gestión Integral de la Calidad Universitaria, Bogotá, Colombia. Bióloga, especialista en Educación Ambiental, Ecoturismo y Gestión de la Calidad y candidata a magíster en Filosofía Latinoamericana. E-mail: marialopez@usantotomas.edu.co 
que permitan diversidad para enfrentar la acción homogenizante de performatividad enunciada por Lyotard (1990). Al finalizar el documento se describe un caso de ejercicio multidisciplinar real y práctico, que ha dejado resultados concretos sobre cómo una disciplina empieza a revisarse a sí misma para gestar caminos de comunicación con otras disciplinas.

Palabras clave: ciencia y humanismo, fragmentación cienciahumanismo, universidad contemporánea. 


\title{
Linkage science and humanism:
}

\section{New perspectives in higher education}

\begin{abstract}
This essay analyzes the fragmentation that occurs in the modern university between science and humanism, in order to see the consequences of modernity in the field of learning and knowledge. Finally, it aims not only to describe this fragmentation, but some proposals to establish escape routes in the approach to new prospects in higher education. To start propose the following questions, which will be resolved during the analysis, or by generating other questions: What are the forces that articulate or dismantle the relationship between science and humanism in the Modern University? What are the ways of relating that generate these forces? What science idea is established in this or these anyway? How do these modes affect, determine or establish different patterns in Higher Education?
\end{abstract}

Along the parallel analysis will approach fragmentation problem and potential solution paths.

They begin by stating the problem of fragmentation between science and humanism as if they were two cultures, then reviews the incursion of an element represented in the social sciences, resulting in not two but three cultures.

Issues related to knowledge, science model and the concept of reason, are reviewed to continue analyzing fragmentation proposing that science and humanism is another manifestation of the so-called liquid modernity, reported by Bauman as a sociological proposal (2002). Then the fragmentation of science and the 
humanities in higher education showing some aspects related with the historic complaint about the rescue of the subject installed in the world of life, philosophical and scientific task based on reality, openness to other rationalities in order to maintain contact with life and recognizing the limits of own discipline. Other ways can recognize the hermeneutic character of science, the need for new humanism open not only to reflect on the past, but today's new challenges. Finally the output to overcome or minimize fragmentation within the university, it is proposed to transdisciplinarity and knowledge dialogue as ways of building new epistemes, allowing diversity to face performativity homogenizing action enunciated by Lyotard (1990). At the end of the paper describes a case of real and practical multidisciplinary exercise that has left concrete results on how a revised discipline begins to take shape itself to communication paths to other disciplines.

Keywords: Science and humanism, science-humanism fragmentation, contemporary university. 


\section{A fragmentação entre ciência e humanismo na universidade contemporânea}

\section{RESUMO}

Através deste ensaio propõe-se realizar a fragmentação que é apresentada na universidade moderna entre a ciência e o humanismo, tendo em conta as consequências da modernidade no campo da aprendizagem e do conhecimento. No final, visa não só para descrever essa fragmentação, mas estabelecer algumas propostas para dar meios de egresso na abordagem a novas perspectivas na educação superior.

Eles começam por afirmar o problema da fragmentação entre ciência e humanismo, como se fossem duas culturas; em seguida revista-se a incursão de um elemento mais representado nas ciências sociais, resultando em três culturas. Todo o relacionado com o conhecimento, o modelo de ciência e o conceito de razão revisam-se para continuar com a análise propondo que a fragmentação entre ciência e humanismo é outra manifestação da chamada modernidade líquida, proposta sociológica referida por Bauman (2002). Por último, para superar ou bem para minimizar a fragmentação dentro da universidade, propõe-se à transdisciplinariedade e o diálogo de conhecimentos como maneiras de construção de novos saberes, que permitam a diversidade para afrontar a ação homogenizante de performatividade apresentada por Lyotard (1990). No final do documento descreve-se um caso de exercício multidisciplinar real e prático, que tem deixado resultados concretos sobre o como uma disciplina começa a se revisar a sim mesma para gestar caminhos de comunicação com outras disciplinas.

Palavras-chave: ciência e humanismo, fragmentação ciência- humanismo, universidade contemporânea. 


\section{INTRODUCCIÓN}

La ciencia no puede ser una "mercancía" como mera "tecnología" valorada por el "precio":

La investigación científica tiene una especie de carácter dramático. Ideas inteligentes pueden llevar a un callejón sin salida; observaciones banales pueden conducir a resolver un problema. Este es el precio que pagamos por el hecho de que la ciencia es un diálogo con la naturaleza, no un monólogo que podamos proseguir a nuestro arbitrio [...] Mi consejo a los jóvenes es que acepten correr riesgos, pero únicamente si lo hacen movidos por un convencimiento profundo. El éxito de la ciencia occidental no se explica solamente por actitudes pragmáticas: la ciencia también ha ido construyendo una filosofía de la naturaleza. Piénsese en Galileo, Newton o Einstein. Hoy se corre el peligro de que la ciencia sea considerada apenas una herramienta técnica o económica; creo que en tal caso perderá su atractivo para muchos de los miembros más dotados de la generación joven. Debemos preservar la base humanística de la ciencia. Debemos verla como parte de la cultura.

Ilya Prigogine ${ }^{1}$

Ilya Prigogine fue premio Nobel de Química de 1977. Nació el 25 de enero de 1917 y murió el 28 de mayo de 2003, a la edad de 86 años en Bruselas, ciudad donde residía. Fue precursor de la teoría del caos y gran filósofo humanista. Sus conclusiones nos ayudan a comprender por qué existimos y por qué los orígenes de la vida no fueron coincidencia.
La anterior cita es una llamada a la urgencia por la recuperación de la unidad de la cultura y el rescate de su poder "hermanador". Ante las presiones actuales a nivel económico que propenden a la separación de la humanidad, se hace perentorio recuperar la capacidad de mantenernos unidos en la diversidad. El siguiente análisis hace parte de un seminario de trabajo en el interior del grupo Pludehuco, donde se quería estudiar la articulación entre ciencia y humanismo en la universidad contemporánea.

\section{¿Dos culturas?}

¿La ciencia y el humanismo están separados?, comparto la opinión de Aguirre (2002) de que se trata de un espejismo planteado por autores como Snow (1977), quien hablan de dos culturas: la humanista y la científica; a la primera pertenecen los literatos y estudiosos de las humanidades y a la segunda, los matemáticos, físicos y otros científicos. Por esta parcelación se ha creado una especie de "competencia de bandos": aquellos que están en el terreno de las humanidades optan por pensar que han perdido una especie de carrera mítica, donde los humanistas se ven a sí mismos como depositarios de los valores de la cultura y se han configurado como guardianes de la tradición, por ello cuando se habla del "ascenso imparable de la ciencia" frente a la "decadencia de las humanidades" los humanistas prefieren pensarlo al contrario, que es el resto del mundo el que está en decadencia y ellos poseen el tesoro acumulado por los siglos; sin embargo, "un tesoro guardado no es riqueza" (Aguirre, 2002, p. 3).

Es importante destacar que no existen "dos culturas", "No existe una 'cultura' que se 
desprenda de la Ciencia, un conocimiento científico, y un conocimiento humanista vinculado con la tradición" (Aguirre, 2002, p. 4). Si esto fuera verdad entonces quienes se ocuparían de mantener vivo el legado de otros tiempos serían únicamente los humanistas, mientras que los científicos se ocuparían de aumentar el conocimiento adentrándose en el presente y mirando hacia el futuro. Según este planteamiento, para la ciencia el pasado sería un lastre que debe ser superado por la propia dinámica del progreso del conocimiento: el pasado sería algo que se aleja. "Desgraciadamente, este es el planteamiento que se ha mantenido vigente y que ha servido, asimilado por las dos facciones o los dos bandos, para separarlas. Pensar en estos términos es un error que estamos pagando todos" (Aguirre, 2002, p. 4).

Según Aguirre, admitir que la ciencia está separada de la cultura es una contradicción que afecta a la raíz misma del pensamiento humanista:

\begin{abstract}
El Humanismo es tener al ser humano, en todas sus dimensiones, en el punto de mira, como referencia constante. Es tener en cuenta que es el Hombre quien produce el conocimiento y también su destinatario final. El conocimiento es un elemento consustancial al Hombre porque es el ser humano quien lo produce, quien lo maneja y quien lo padece o disfruta (Aguirre, 2002 p. 4).
\end{abstract}

Entonces, ¿por qué existe no solo una percepción de desarticulación entre la ciencia, la filosofía y las humanidades, sino concepciones que hacen real la parcelación del conocimiento y lo fracturan sobre todo en la educación superior? Otras luces puede darlas el modelo de las tres culturas.

\section{Tres culturas}

En la ilustración europea del siglo XVIII, se consolida el pensamiento científico, por cuanto la razón se constituyó en el punto central para explicar el mundo. Esto implicaba una fe en el orden de la naturaleza y por tanto en la búsqueda de las leyes que la rigen para comprenderla tal como si fuera una máquina. Por lo anterior, desde este punto de vista aún a la ciencia se le clasifica, o mejor se le define, con los lentes de una perspectiva mecanicista, la cual heredó el positivismo:
Es curioso cómo la visión que se tiene de la Ciencia desde el campo de las Humanidades tiene muy poco que ver ya con la Ciencia actual. Alejados de ella, se conserva una visión de la Cien- cia más propia de los tiempos del posi- tivismo, planteamiento que en gran me- dida ha sido abandonado en el propio campo científico. La Ciencia del siglo XXI ya no es la Ciencia del siglo XIX (Aguirre, 2002, p. 4).

Sin embargo, respecto a esta idea, si bien se puede aplicar en amplios sectores científicos y grupos de investigación orientados a nuevos paradigmas - como la teoría general de los sistemas, teoría de las estructuras disipadas, el cerebro holográfico, teoría de la resonancia mórfica, la hipótesis Gaia, el Tao de la física, entre otros-, aún existen posturas científicas que, aunque no se pueden calificar como recalcitrantes, aparecen usando modos de producir el conocimiento de tipo "tradicional" - entiéndase este 
calificativo como aquel que estudia al objeto como un algo separado con pretensiones de explicación objetiva por parte del sujeto que lo observa-.

Todo lo anterior es resultado de un largo camino recorrido desde los años sesenta, en los cuales las ciencias naturales empezaron a virar hacia

procesos que destacaban la no linealidad por encima de la linealidad, también la complejidad sobre la simplificación, la imposibilidad de eliminar al que mide de la medición, e incluso, para algunos matemáticos, la superioridad de una amplitud interpretativa cualitativa por encima de una precisión cuantitativa cuya precisión es más limitada (Wallerstein, 2006, p. 67).

Así, las ciencias naturales se acercaban a aquellas que tanto despreciaban como ciencias blandas, en el sentido de que ya no concebían a la naturaleza como pasiva sino más bien como activa y creativa, es decir que la mayoría de los científicos comprenden que este mundo es mucho más complejo, y en él las perturbaciones desempeñan un papel muy importante, donde se hace necesario dar cuenta de esa complejidad y se ha roto con la idea exclusiva de que lo macroscópico pueda ser en principio deducido de un mundo microscópico más simple. Hoy en día ya muchos postulan que los sistemas complejos se autoorganizan y por tanto, como se mencionó, es posible hoy no considerar que la naturaleza sea pasiva (Wallerstein, 2006, p. 68).

Al comienzo de este escrito se indicó el problema de las dos culturas; al respecto
Wallerstein (2006), en su afán de generar un análisis reflexivo sobre la situación de las ciencias sociales, menciona el problema de la estructura de conocimiento que proviene de los extremos opuestos que resultan de las divisiones universitarias del conocimiento, cuestionando la realidad y validez de la distinción entre las "dos culturas". Para este autor la cuestión no es binaria sino tripartita, y dice que antes de 1945 las ciencias sociales se encontraban interiormente divididas entre las dos culturas: entre las humanidades y las ciencias naturales (Wallerstein, 2006, p. 74).

Sin embargo, lo que se puede apreciar hoy es que existen aperturas desde las ciencias naturales hacia las ciencias sociales y viceversa, o bien aperturas de las ciencias naturales hacia las humanidades recíprocamente. Como ejemplos de estas conexiones se encuentran los métodos de análisis complejos, que se comprenden desde las ciencias naturales para realizar estudios en ciencias sociales y que tienen amplios alcances, como el problema de la relación entre innovaciones estocásticamente generadas y fluctuaciones económicas de largo plazo o la comprensión de sistemas sociales históricos compuestos por múltiples unidades interactuantes, caracterizadas por el surgimiento y la evolución de estructuras y organizaciones jerárquicas internas, y comportamientos espacio-temporales complejos (Wallerstein, 2006, p. 70).

Se evidencia que ya hay más debates sobre las distinciones y, según Wallerstein, parecería que "avanzamos en dirección a una visión menos contradicitoria de los múltiples campos de conocimiento [...]" (Wallerstein, 2006, p. 75). Parece además que los puntos 
de acercamiento se hacen hacia los puntos de vista tradicionales de las ciencias sociales; la pregunta es si esto significa que se pueda superar el concepto de las dos o tres culturas. Es prematuro afirmarlo todavía, pero lo que sí está claro es que

\begin{abstract}
la división tripartita entre ciencias naturales, ciencias sociales y humanidades ya no es tan evidente como otrora parecía. Además ahora parece que las ciencias sociales ya no son un pariente pobre, de alguna manera desgarrado entre los dos clanes polarizados de las ciencias naturales y las humanidades: más bien han pasado a ser el sitio de su potencial reconciliación (Wallerstein, 2006, p. 75).
\end{abstract}

Aquella ciencia moderna considerada en sí misma como la "más racional, "más dura" y más precisa, más poderosa, más seria, más eficaz y, por lo tanto, de consecuencias más importantes que la filosofía o las artes y las letras" (Wallerstein, 2006, p. 72), enfrentada a los cambios sociales, económicos y ambientales de la últimos cincuenta años, se queda corta al dar respuestas debido a que la realidad le reclama respuestas no precisamente enmarcadas en una racionalidad restrictiva.

Es por ello que ejemplos de esta realidad que desborda las premisas de la ciencia moderna han dado nuevas reacciones, como son los estudios culturales. Entre los desafíos que se proponen están, entre otros, el estudio de los sistemas sociales históricos, los estudios de género y estudios "no eurocéntricos", los cuales conducen a reconocer una interpelación dentro de las humanidades, las ciencias naturales y las ciencias sociales de reflexionarse epistemológicamente, éticamente y antropológicamente.
Todo lo anterior nos lleva a pensar que, en los estudios alternativos y los estudios culturales, hay un escepticismo en los méritos del progreso tecnológico (desde posturas moderadas hasta el repudio extremo); méritos que han tomado forma en una especie de "regreso de la filosofía" donde los enfoques hermeneúticos recuperaron su terreno, y son clave para la reflexión epistemológica de las disciplinas sobre sí mimas (Wallerstein, 2006, p. 73). Es por ello que se amerita revisar el modelo de ciencia.

\section{El modelo de Ciencia}

Edmond Husserl (1936) ${ }^{2}$, en su revisión sobre la crisis de las ciencias europeas y en la crítica que hace a Descartes, denunció con claridad que para delinear o definir las ciencias no se puede tomar como modelo ninguna ciencia en particular. Al respecto, el filósofo Daniel Herrera (1986) menciona:

Desde las Investigaciones Lógicas el pensamiento de Husserl fue muy explícito en este punto: si queremos saber qué es la ciencia, no lo lograremos ni a partir de una comparación entre las diversas ciencias ni tomando como modelo una determinada ciencia, tal como lo hicieron Descartes y Kant. El punto de partida no puede ser otro que el análisis fenomenológico de la actividad misma del científico, de la intención que mueve a éste, intención que ninguna ciencia en vía de constituida logra realizar (p. 236).

2 Edmund Husserl nació en 1859 Prossnitz (Moravia) y falleció en 1938 en Friburgo. Fue un filósofo que fundó la fenomenología transcendental. Su obra La crisis de las ciencias europeas y la fenomenología trascendental sale a la luz en 1936. 
En ese sentido, Husserl critica a Descartes, pues este último le confirió a la ciencia físicomatemático un carácter definitivo, postulando una verdad absoluta a partir de la ciencia galileana. La idea de verdad absoluta es una posesión histórica del hombre $\mathrm{y}$, en cuanto tal, pertenece al mundo (Herrera, 1986, p. 236), justamente a ese mundo del cual quiere dudar. Por lo anterior, para Husserl, además del mundo de la experiencia, también las verdades científicas deben ser sometidos a la duda, debido a que son un producto histórico de la praxis del hombre (Herrera, 1986, p. 236).

Es por ello que la reflexión de Husserl propone que el punto de vista cartesiano supone una teoría de las ideas como imágenes separadas y distintas del mundo, lo cual refuta porque considera que es fenomenológicamente falsa, ya que "toda adquisión de la ciencia funda su sentido en la experiencia inmediata y reenvía al mundo de esta experiencia" (Herrera, 1986, p. 238). Es así como el filósofo alienta a dejar una actitud "natural" y asumir la actitud filosófica o científica frente a la realidad, pero siempre sobre el "suelo de este mundo de la vida, presupuesto para todos los proyectos de conocimiento. Es pues el suelo para toda teoría de la ciencia" (Herrera, 1986, p. 238). Por la necesidad de avanzar en el análisis no me detendré más en la crítica que hizo Husserl a Descartes en cuanto a las limitaciones del ego cartesiano, pero traigo a colación su reflexión con el ánimo de rescatar la postura de su comprensión del sujeto donde no hay separación entre este y el mundo, sino una unidad, pero unidad entre dos seres, la unidad del sujeto y del mundo, en cuanto constituído por el sujeto, es relativo a este, lo cual lo catapulta a preguntarse por el sentido de las cosas (en términos husserlianos, que implica entre otras cosas poner el mundo en paréntesis).

Heredando la discusión y crítica que hizo Husserl en su momento a la crisis de la ciencias y también al poner alertas al excesivo cientificismo que se vivía por la época, se denuncia que las ciencias han renunciado a su propia cientificidad por reducir la verdad a la facticidad, con lo cual se ha desarrollado en las ciencias del siglo XIX y parte del XX una imagen absurdamente estrecha de la racionalidad.

Siguiendo con esta crítica, a partir de 1945, los planteamientos de Husserl tomaron mayor vigor a causa de la crítica moderna y los cuestionamientos de la realidad en cuanto a la incoherencia entre praxis y teoría de la escuela de Frankfurt, las críticas al positivismo desde esta misma escuela y otros sectores, hasta el escepticismo postmoderno, las revisiones en el interior de las ciencias sociales y de las ciencias naturales, que entre otras suponen una revisión sobre el concepto de razón.

\section{EL CONCEPTO DE RAZÓN}

Para Vitoria (2011) el concepto de razón dominante en la modernidad tuvo su máxima expresión en la ilustración, el positivismo y el neopositivismo, donde la razón se redujo o más bien se definió en términos de lo empírico de aquello que se es susceptible de someter a medida o a cálculo, por ejemplo

\footnotetext{
[...] para el positivismo, la ciencia - es decir, la totalidad del saber racional - consiste en la observación y
} 
medida de los "hechos" o fenómenos empíricos y en la formulación de las leyes que los relacionan, para poder prever la evolución de los sistemas y dominar el mundo. La investigación de las causas en cualquier nivel de estudio, o el interés por conocer lo que pertenece a la identidad misma de las cosas, serían tareas obsoletas, superadas históricamente por el saber científico (Vitoria, 2011, p. 51).

Este tipo de concepción trae consigo consecuencias muy claras: todo aquello que no encaje en el horizonte empírico no tiene respuesta racional, por ejemplo,

\begin{abstract}
Las cuestiones antropológicamente más relevantes, como son las preguntas sobre el significado último del mundo, sobre el origen y el sentido de la vida humana, o el juicio acerca de diversas concepciones de la vida buena, o sobre el carácter más o menos razonable de una religión en relación con otra (Vitoria, 2011, p. 51).
\end{abstract}

Todo lo anterior más bien se ubicaría en una especie de saco no racional del "ánimo humano". Esto entonces hace que "la razón como tal no sería capaz de reconocer como malo lo que ofende a la dignidad del hombre, ni como bueno lo que la promueve" (Vitoria, 2011, p. 51).

Las denuncias ante esta forma de concebir la razón no se han hecho esperar, sobre todo desde finales del siglo XIX y comienzos del siglo $\mathrm{XX}$, con las fuertes críticas que hace la fenomenología y las filosofías existencialistas en torno a la superación del cientificismo, entre sus representantes más representativos está Edmund Husserl quien rescató al sujeto como medio de reconducción de las ciencias - o Heidegger - quien criticó el predominio de la razón técnica e instrumental de la cultura, la cual había conducido a desestimar las dimensiones del pensamiento y de la libertad, esenciales para el ser humano, hasta el punto de olvidarlas - . El desvelamiento del ser se había ahogado por el pensamiento calculador, por ello Heidegger denuncia este "olvido del ser" (Seinsvergessenheit) en el que ha caído la sociedad occidental (Vitoria, 2011, p. 52).

Igualmente, desde la teoría crítica propuesta por la escuela de Frankfurt con autores que van desde Horkheimer, Adorno hasta Habermas, se abandera una reflexión en torno a la razón, la cual proponía extender su concepto, de manera que el pensamiento se liberara de los límites marcados por la práctica empirista y de una visión objetiva de la realidad, cuestionando las falsas promesas de bienestar de una razón meramente instrumental para superar los enajenamientos de la teoría tradicional y remplazar un concepto taxativo de razón por uno crítico, más amplio e intersubjetivo. Particularmente, Max Horkheimer apuntó su crítica al positivismo en el libro Crítica de la razón instrumental (1946), donde denuncia que "mediante su identificación de conocimiento y ciencia el positivismo limita la inteligencia a funciones que resultan necesarias para la organización de un material ya tallado de acuerdo con el molde de la cultura comercial" (p. 55). Según Horkheimer, la noción de razón que sirve de base para la cultura industrial ha ido de la mano con el avance progresivo de los medios técnicos, el cual se ve acompañado por un proceso de deshumanización. 
En el pasado en escuelas como las de Platón y Aristóteles, la escolástica y el idealismo alemán se basaban en una teoría objetiva de la razón, la cual aspiraba a desarrollar un sistema vasto o una jerarquía de todo lo que es, incluido el hombre y sus fines; entonces, el grado de racionalidad de la vida de un hombre podría determinarse de acuerdo con esa armonía con la totalidad. La estructura objetiva de esta, y no solo el hombre y sus fines, debía servir de pauta para los pensamientos y las acciones individuales. Dicho concepto de razón no era excluyente con el concepto de razón subjetiva; esta forma de pensar concilia el orden objetivo con la existencia humana, es decir, esta definición de razón es inherente a la realidad y no se tenía como foco la correspondencia entre conducta y fines, sino más bien - como se muestra en la Republica de Platón - la idea del bien supremo y la manera de realizar las metas supremas, es decir, un hombre era racional cuanto más afortunado y feliz fuera en su vida.

Esta idea se contrapone a la idea de razón como capacidad subjetiva del intelecto para organizar instituciones de "manera racional" aplicando su facultad lógica y calculadora, instauradas entre otros por las ideas filosóficas de John Locke. Entonces, se empieza a equiparar razón con capacidad de calcular probabilidades y adecuar así los medios correctos a un fin dado. Facultades como la discriminación y la reflexión también ayudan a la adecuación de los medios a los fines, lo cual ha sido el interés no solo de la ciencia, sino la razón de ser de toda teoría dentro del proceso de producción social (Horkheimer, 1973). La crisis de la razón que anunciaba Horkheimer tiene hoy vigencia en cuanto a que la razón se mecaniza cuando solo se le otorgan valor a los procesos mentales que se basan en las matemáticas y la lógica (lo cual por supuesto es esencial para el desarrollo industrial, pero no puede ser la única válida). Por lo tanto, la razón se instrumentaliza y se enceguece; en palabras del autor: se torna fetiche, entidad mágica, más aceptada que experimentada espiritualmente (Horkheimer, 1973, p. 20).

Las consecuencias que pagamos no solo en los tiempos de la postguerra (cuando fue escrito el libro), sino en los tiempos actuales, es que nociones como las de justicia, igualdad, felicidad y tolerancia que en siglos anteriores eran inherentes a la razón o pendientes de ella ahora han perdido sus raíces originarias, se les considera metas y fines pero no hay ninguna instancia racional autorizada para otorgarles valor o vincularlas con una realidad objetiva (Horkheimer, 1973, p. 35). La tradición humanista que preserva los aspectos racionales antes mencionados (justicia, igualdad) se constituye en venerables documentos que son preservados por los filósofos o historiadores, pero que carecen de una confirmación por parte de la razón en su sentido moderno, ya que solo existe una autoridad que puede decidir si estos valores son verdad: la ciencia, pero concebida como clasificación de hechos y cálculo de probabilidades. En ese marco de ideas, la justicia y la igualdad son mejores que la injusticia y la opresión, pero como no son científicamente verificables, su estudio carece de sentido.

Por otro lado, retomando de la cultura griega, las expresiones como civilización, cultura, tradición, literatura o educación, que en nuestro lenguaje están separadas debido a 
las terminologías modernas, están constituidas en una unidad originaria denominada paideia. Para los griegos la educación y la cultura no constituyen un arte formal o una teoría abstracta, distintos de la estructura histórica objetiva de la vida espiritual de una nación. Los valores de esta cultura toman cuerpo en la expresión real de toda cultura: la literatura. La paideia no es un aspecto externo de la vida (Jaeger, 2001, p. 13), en este concepto se enraiza una forma de vida, un ideal de cultura.

En los griegos el concepto de razón pretendió tener una mayor amplitud que abarcara tanto nuestro origen como nuestro destino. Aristóteles (1998, citado por Vitoria, 2011, p. 53) inicia su Metafísica diciendo que "todos los hombres tienen el deseo natural de saber", de conocer la verdad. Por ello los griegos se hicieron preguntas significativas como ¿cuál es el origen de las cosas? y ¿cuáles es el trasfondo que sustenta las cosas? Estos cuestionamientos de los griegos permiten ver que tenían una concepción de la razón que se preguntaba por "la totalidad de la realidad y por el sentido de todo": una razón orientada tanto a indagar sobre las realidades naturales como a indagar sobre la inmortalidad del alma sobre la naturaleza de Dios. Así mismo, dicha racionalidad estaba abierta a una pluralidad de recorridos: adyacente a la demostración científica, había espacio para la dialéctica, la retórica, la poética y la sofística. "Esto significa que el pensamiento griego consideraba que el simbolismo estético, la intuición, las tradiciones, la fe y otros tantos caminos, podían conducir válidamente a la verdad, quizá allá donde la razón demostrativa no lograba llegar" (Sanguineti, 1992 y Berti 1989, citados por Vitoria, p. 54).
Es claro que entre el concepto de razón griega y el de razón de la modernidad dominante actual hay una diferencia notoria, pues en esta última la razón se impone una autolimitación que le impide buscar otros fundamentos de la realidad que no se enmarquen en realidad empírica y el sentido de todo, sin que le produzca una sensación de abatimiento (Vitoria, 2011, p. 55). También es clara la nueva concepción de la posición del individuo en la sociedad que le dieron los griegos en comparación con las culturas de la antigüedad, lo cual conlleva su importancia universal como educadores, conscientes desde el comienzo de que la educación es el principio mediante el cual la comunidad humana conserva y transmite su peculiaridad física y espiritual, y conscientes también de que con el cambio de las cosas cambian los individuos, y el hombre propaga y conserva su forma de existencia social y espiritual mediante las fuerzas por las cuales las ha creado, es decir, mediante la voluntad consciente y la razón (Jaeger, 2001, p. 10). De aquí que la razon griega concebia la naturaleza en un sentido innato y las cosas del mundo desde una perspectiva tal que ninguna de ellas estaba separada y aislada del resto, sino como un todo ordenado en una conexión viva, en la cual y por la cual cada cosa alcanzaba su posicion y su sentido (Jaeger, 2001, p. 15). Después de revisar el concepto de razón, el cual determina el modelo de ciencia, a continuación se analizan posibles mecanismos que dan cuenta de la ruptura entre ciencia y humanismo.

\section{Traición A los sólidos}

La concepción de la ciencia que da preponderancia a su valor materialista causó de 
alguna manera una "traición" a la tradición epistemológica y filosófica en la manera como se concebía el conocimiento científico. Esto podría relacionarse con lo que Bauman (2002) define como la modernidad líquida. Modernidad líquida definida como el proceso de licuefacción; proceso por medio del cual se derriten los sólidos (Bauman, 2002, p. 9). Según esta explicación, en la historia una de las tradiciones sólidas fue la relación entre ciencia y humanismo; era tan sólida que ni siquiera se podían percibir divisiones, simplemente se hablaba de una forma de hacer ciencia totalmente ligada a las humanidades, pues eran una sola. Bauman lo ilustra mejor en su definición: "Entendiéndose por sólidos a aquello que persiste en el tiempo, que es indiferente a su paso e inmune a su fluir, a las estructuras congeladas, la sociedad estancada, resistente a cambios, todo lo anterior le representada al espíritu moderno un obstáculo para sus proyectos" (Bauman, 202, p. 9). Lo anterior no significó derretir todos los sólidos ni liberar al mundo de estos para siempre, sino hacer espacio a "nuevos y mejores sólidos", algo así como en una nueva condensación de líquidos a sólidos, para generar sólidos confiables y de los que se pueda depender. Para lograr semejante licuefacción, se requiere profanación de lo sagrado, desautorización y negación del pasado, negación de la tradición (sedimento y el residuo del pasado en el presente) y destrucción de la armadura protectora forjada por las convicciones y lealtades que permitían a los sólidos resistirse a la licuefacción.

La licuefacción que señala el autor se está refiriendo al paso de la modernidad sólida (pautas sagradas basadas en lealtades tradicionales) a la modernidad líquida (ruptura de estas pautas); un paso de un ámbito donde no hay una invasión y total dominio de la racionalidad instrumental (rol determinante de la economía en la vida social); el paso desde un orden determinado por un engranaje cultural interdependiente entre política, economía y sociedad hacia un orden enteramente determinado por el rol de la economía: dominando la totalidad de la vida humana, volviendo irrelevante e inefectivo todo aspecto de la vida que no contribuyera a su incesante y continua reproducción.

Dentro de las lealtades tradicionales que menciona Bauman, se propone acá incorporar la relación entre ciencia y humanismo que poco a poco a lo largo de la modernidad se fue desmantelando y causó el tipo de racionalidad ilustrada, separada de los demás componentes denominados erróneamente "no racionales" de carácter humanístico que escapan al encuadre empírico o bien dándole a la ciencia un valor casi exclusivo en relación con su aplicabilidad tecnológica, dejando de lado los otros aportes humanísticos que la ciencia pueda tener.

El momento de la modernidad líquida ha derretido los sólidos que representaban los vínculos entre las elecciones individuales y los proyectos y las acciones colectivas - las estructuras de comunicación y coordinación entre las políticas de vida individuales y las acciones políticas colectivas (Bauman, 2002, p. 12).

Si bien Bauman se ubica preponderamente en el terreno político, sus análisis se pueden extender a las rupturas entre la ciencia y el humanismo que ocupan el presente análisis, pues estas representan una forma más de elección individual, de racionalidad 
tecnocientífica que pretende proteger y satisfacer al individuo sacrificando los intereses colectivos, por ello otra manifestación de la ruptura entre ciencia y humanismo es el individualismo contemporáneo.

Por supuesto todo esto es resultado de una trayectoria histórica de hechos económicos donde el liberalismo clásico (el principio del laissez-faire), el libre juego de la oferta y la demanda, la coincidencia entre interés individual y beneficio social se fueron distanciando a tal punto que, como lo llama Bauman, nos encontramos hoy con el capitalismo liviano:

\begin{abstract}
En el Mundo del capitalismo liviano, no se encuentran quien escriba sobre utopías de una buena sociedad, todo recae sobre el individuo: solo a él le corresponde descubrir qué es capaz de hacer, ampliar esa capacidad al máximo y elegir los fines a los cuales aplicar esa capacidad, lo que significa la mayor satisfacción (Bauman, 2002, p. 67).
\end{abstract}

En resumen, el autor hace una "radiografía" de la problemática de la individualidad contemporánea, lamenta que exista una escasez de potenciales revolucionarios, de gente capaz de articular el deseo de cambiar su situación individual como parte de un proyecto de cambiar el orden de la sociedad desde las acciones colectivas. En ese sentido el diagnóstico apunta hacia un llamado crítico a los ejercicios globalizantes que enfrenta la sociedad, la cual está asumiendo estos procesos sin ni siquiera darse cuenta $\mathrm{y}$ sin ningún filtro que frene su efecto homogeneizador, hecho que afianza contradictoriamente la individualidad centrada en el consumismo y no en la diversidad creadora con mayor posibilidad de formar proyectos de vida que equilibren las acciones individuales con las acciones colectivas. Es por ello que las lealtades tradicionales que son necesarias rescatar son aquellas que restablecen la fractura entre ciencia y humanismo, reconociendo que la reflexión humanista está sometida a estos nuevos moldeamientos de la condición humana, de los cuales no nos libramos tan fácilmente, pero a la vez se configuran como retos por tener en cuenta.

En la universidad contemporánea la traición a los sólidos tiene su máxima expresión en lo que Lyotard denuncia como "la crisis de legitimación de la universidad contemporánea en el marco del capitalismo postfordista" (Lyotard, 1990, citado por CastroGómez, 2007).

Según, Castro-Gómez (2007), la universidad es el lugar donde se legitima el saber y es vista no solo como el lugar donde se produce el conocimiento que conduce al progreso moral o material de la sociedad, sino como el núcleo vigilante de esa legitimidad (p. 81). Sin embargo, dados los nuevos imperativos de un entorno planetario y de un mercado global, dicha legitimación del saber en la universidad se pliega ante estos nuevos condicionantes y entra en crisis. Las preguntas originarias como ¿es eso verdad? son remplazadas por ¿para qué sirve?, ¿se puede vender? (mercantilismo) o ¿es eficaz? (ejercicio de poder). Ante esta evidencia, Lyotard y en general los postmodernos develan la nueva condición de la universidad, la cual a pesar de ser una institución que busca la verdad, no puede negar que ha sido presionada por la industrialización desde su 
resurgimiento en el siglo XIX, y hoy en cierta forma se "le quieren cobrar los favores del pasado", haciendo de la universidad centros de reproducción de intereses empresariales e industriales, que Castro-Gómez denuncia de la siguiente manera:

El principio de performatividad tiene por consecuencia la subordinación de las instituciones de educación superior a los poderes globales. La belle epoque del profesor moderno, la era del "educador" y del "maestro", parece haber llegado a su fin, pues la función de la universidad hoy día ya no es educar sino investigar, lo cual significa (abre cita) producir conocimientos pertinentes. Los profesores universitarios se ven abocados a investigar para generar conocimientos que puedan ser útiles a la biopolítica global en la sociedad del conocimiento. De este modo, las universidades empiezan a convertirse en microempresas prestadoras de servicios (Castro, 2007, p. 85).

El panorama no parece alentador a esta altura de la discusión, pero puede haber algunos caminos en los cuales se puedan intentar algunas rutas para la solución de las fracturas enunciadas.

\section{Fragmentación entre}

\section{LA CIENCIA Y LAS HUMANIDADES EN LA EDUCACIÓN SUPERIOR, ALGUNAS SALIDAS}

Antes del XVII no se establecía una diferencia tajante entre la ciencia y la filosofía, ambos significaban conocimiento y la gente las concebía como algo relacionado o si se quiere superpuestas de algún modo, no de manera intercambiable pero si relacionadas (Wallerstein,2006).
A fines del siglo de las luces asistimos al nacimiento, antes referenciado, de lo que C. P. Snow (1977), denominó "las dos culturas". La ciencia comenzó a de- finirse por su contenido empírico, a ser entendida ante todo como una búsque- da de la verdad a través de la investiga- ción, a diferencia de lo que estaban ha- ciendo los filósofos, especular o deducir de algún modo. Fue una continuación de la ruptura entre la filosofía y la teolo- gía; aquí se daba un paso más hacia un sistema de conocimiento íntegramente secularizado (Wallerstein, 2006, p. 5).

Todo lo anterior está enmarcado en los acontecimientos de finales de los siglos XVIII y XIX en Europa, donde sucedían cambios tan grandes que marcaron la historia de la humanidad, en hechos tan cruciales como los ocurridos en el neolítico

Representados en el avance de la industrialización sobre la tradicional economía agraria, el incremento de la productividad y el desarrollo espectacular de la economía capitalista, el estímulo constante a la innovación científica y tecnológica aplicada a la producción, la revolución de los transportes y las comunicaciones, la expansión comercial de las naciones industrializadas y el despliegue del imperialismo sobre los pueblos menos desarrollados de Asia y África, el desencadenamiento de grandes movimientos migratorios y la restructuración de las relaciones sociales, con el desplazamiento de la sociedad aristocrática propia del Antiguo 
Régimen por una nueva sociedad burguesa y el surgimiento del movimiento obrero (Sanz, 2012, p. 1).

Las nuevas condiciones que se describen traen consecuencias que hicieron de las ciencias (tanto naturales como sociales) servidoras de la producción económica, que se manifestaron sobre todo durante la segunda revolución industrial, donde las innovaciones tecnológicas "fueron muy abundantes sobre la base de una constante transferencia de descubrimientos científicos a la producción económica: por ejemplo el relevo del carbón, el vapor y el hierro, emblemas de la primera revolución industrial, por el petróleo, la electricidad y el acero" (Sanz, 2012, p. 6).

Lo anterior nos sirve como marco de referencia para precisar las condiciones económicas que desencadenaron lo que, según Wallerstein (2006) en nota introductoria de la traducción de Cubides (2006), sucedía mientras se gestaba el divorcio entre la ciencia y la filosofía (de las humanidades en general) y se operaba un resurgimiento de la universidad (institución prácticamente en receso desde el siglo XVI) que ya en el siglo XIX se constituyó en un recinto para la creación de conocimiento y su reproducción.

Por esta razón, se fueron constituyendo lo que conocemos como disciplinas dotadas de cátedras con departamentos que otorgaban títulos académicos. Esta innovación es muy reciente (está aproximadamente entre 1850 y 1914). Todos los campos de intereses se condensaron en parcelas de conocimiento que se convirtieron en "departamentos, asociaciones profesionales, revistas académicas y en sistemas de clasificación en las bibliotecas (la Biblioteca del Congreso de los Estados
Unidos, por ejemplo, las reproduce como conjunto de categorías en la última década del siglo XIX)" (Cubides, 2006, p. 2).

Al respecto, cabe mencionar la crítica de Husserl a la ciencia moderna mencionada por Lonergan (2008), diciendo que las intenciones originales de la ciencia griega resucitada en el Renacimiento llamada ahora ciencia moderna fueron muy distintas: en la primera se buscaba desplazar el contraste entre ciencia y opinión (episteme y doxa), con el fin de establecer un ideal de conocimiento y verdad a través de procedimientos metódicos, un ideal científico transformando la significación de palabras "ordinarias", como son sabiduría, verdad, inteligencia y ciencia (Lonergan, 2008, p. 111). En el Renacimiento se redescubre el ideal griego del conocimiento y la verdad, pero además se asume este ideal como medio para destruir la opinión y el poder meramente tradicional "para fincar a la sociedad humana sobre una base de verdad y razón, libertad y responsabilidad" (Lonergan, 2008, p. 111).

Husserl parte de este criterio para establecer sus cinco críticas a la ciencia moderna, en las cuales se evidencia esta última no ha cumplido con sus propósitos originales en cuanto a la inspiración universal de proporcionarle al hombre el conocimiento y la verdad oponiéndola a la opinión meramente tradicional, ni tampoco para capacitar al hombre en colocar a la sociedad sobre una base de ciencia y verdad. Por lo anterior, denuncia el autor que la ciencia moderna muestra una tendencia a fragmentarse en especialidades (se puede ver el catálogo de admisiones de una universidad y se encontrará con muchas divisiones, lo mismo en el interior de cada disciplina), una tendencia a 
dividirse. Pero a su vez estos fragmentos toman vida propia, es decir, se vuelven autónomos y lo que es peor para Husserl es que las discusiones sobre el conocimiento, ciencia y verdad son solo otras tantas especialidades y son cuestión de opinión, a excepción de la filosofía que se dedica a la reflexión y discusión de las cuestiones del conocimiento y la ciencia, pero no rige a las demás disciplinas, sino que cada disciplina se rige a sí misma e incluso la filosofía es otro departamento más (Lonergan, 2008, p. 113).

Esto último lo condensa al afirmar que no hay pues ningún fundamento que logre considerarse como la base donde se pueda situar a todas las disciplinas que se han fragmentado, pues se han hecho autónomas, se han orientado únicamente por lo pragmático para obtener resultados y han dejado de lado el mundo de la vida (entre otros, el saber popular) (Lonergan, 2008, p. 114).

Es obvio que de las críticas de Husserl dirigidas a la ciencia moderna surgieron posteriores detracciones que a mi modo de ver son también producto de una profunda visión fragmentaria del conocimiento; hay problemas de las ciencias del hombre que finalmente no pueden ser solucionados por las ciencias naturales o sociales, sino que le competen más a la filosofía y su relación con la teología. Sin embargo, todas estas discusiones pueden ser resueltas de manera simple, pero a la vez compleja, como lo habría hecho Heidegger (1977) en su Carta sobre el humanismo, y así "reducir" o "elevar" todo a la pregunta por el ser.

No obstante, me adhiero al pensamiento de Husserl en su rescate del sujeto en el quehacer científico y más aún en el quehacer educativo universitario, donde es necesario rescatar el aporte del sentido común que nos mantiene - como menciona Schrödinger - en contacto con la vida, pues si bien el quehacer científico implica una mirada o una conciencia o experiencia específicas, no propiamente encajada en el especímen del sentido común; la ciencia debe abrirse o dialogar con los aportes del "suelo de la vida". También considero que los científicos no deben independizar lo que ellos hacen en sus resultados de investigación con la teoría de conocimiento que hizo posible sus resultados. Es decir, las ciencias naturales no pueden ya contentarse únicamente con el criterio pragmático de sus éxitos, sino que deben buscar paralelamente o simultáneamente su sentido y específicar sus relaciones con la filosofía y con las ciencias del hombre, asi como lo hacen las ciencias sociales y humanas, además, y en la medida de lo posible incorporando, lo teológico, tarea algo imposible para la mayoría de los científicos. Así pues, las ciencias ambientales pueden ser un buen ejemplo para dar luz en la generación de intersecciones que generen caminos que den cuenta tanto de lo científico como de lo humanista.

Finalmente, lo que se busca es un intento de unidad para superar la fragmentación entre ciencia y humanismo dentro de la universidad. A propósito, Delpech (2011) retoma a Derrida (1997) cuando se pregunta por la razón de ser de la universidad. Derrida ${ }^{3}$ menciona en su texto Las pupilas de la Universidad. el principio de razón y la idea de la Universidad:

3 Derrida, J. (1997). Las pupilas de la Universidad. El principio de razón y la idea de la Universidad (Traducción de Cristina de Peretti). En Cómo no hablar y otros textos [en línea]. Barcelona: Derrida en castellano. Recuperado de http://www.jacquesderrida. com.ar/textos/universidad.htm 
En la expresión "razón de ser", dicha causalidad tiene sobre todo el sentido de causa final. Está dentro de la tradición de Leibniz, el cual firmó la formulación, que fue más que una formulación, del Principio de Razón. Preguntarse si la Universidad tiene una razón de ser es preguntarse “¿por qué la Universidad?", pero con un "por qué» que se inclina más bien del lado del «¿con vistas a qué?». ¿La Universidad con vistas a qué? ¿Cuál es esta vista, cuáles son las vistas de la Universidad? O también: ¿qué se ve desde la Universidad, ya se esté simplemente en ella o embarcado en ella, ya se esté, al interrogarse acerca de su destinación, en tierra o en alta mar? (Derrida, 1997, p. 1).

Al respecto, y continuando con la preocupación por la reunificacion de la ciencia y el humanismo como razón de ser de la universidad, se rescata la idea de Delpech (2011), cuando señala que "cada filósofo ha sido y es hijo de su tiempo, y esto lo arraiga directamente a la dinámica del suelo histórico al que se ve sometido, al devenir de las generaciones reales" (p. 1), para mostrar que otra manera de hacer filosofía es partir de la realidad, lo cual es extensivo también para la ciencia y en general para el quehacer dentro de la universidad. Para ello destaco como ejemplo la labor crítica que realizaron, según Delpech (2011), Adorno y Levinas a partir de los hechos de Auschwitz, generando una revisión sobre una nueva concepción de la ética del otro. Es decir, en palabras de la autora:

[...] también para interpretar la realidad significa volver sobre los pilares que la configuran y en consecuencia, ven la necesidad de ir más allá de los postulados metafísicos que fundamentan el hecho histórico sobre el que versan. Son la prueba de que, algunas veces, pensar no significa tan sólo un juego de palabras o la búsqueda del saber por el saber mismo, sino la posibilidad de esgrimir un marco teórico que aprenda de sus errores pasados para configurar la posibilidad de un porvenir mejor (2011, p. 1).

El quehacer científico y el filosófico-humanista están basados en la realidad para reflexionar sobre ella, para recapacitar sobre filosofías o teorías científicas pasadas, pero sobre todo para superar la vieja distancia “entre teoría y práctica, idea y acción, y, en consecuencia, la de recordar, y sobre todo demostrar, que el pensamiento es una forma de la realidad" (Serrano, 2000, p. 155).

Entre los posibles caminos que alinean una visión sensata de la ciencia y que posibilite sus relaciones con campos éticos, educativos y prácticos que orienten una relación entre ciencia y humanismo, a continuación se proponen las siguientes salidas: aperturas a otras racionalidades, mantener el contacto con la vida, revisar los límites de las disciplinas, vías de superación de la fragmentación ciencia-humanismo- tales como el uso de la metáfora-, la transdisciplinariedad y el dialogo de saberes y finalmente se ilustra un caso de ejercicio multidisciplinar.

\section{Aperturas a otras RACIONALIDADES}

Si bien la razón griega mencionada anteriormente se retoma con cierta nostalgia, es grato anunciar que las últimas reflexiones 
de la filosofía de la ciencia se han aproximado a la creencia de que el "conocimiento científico no es la única forma rigurosa de racionalidad"; y este conocimiento se ha entendido a sí mismo como un conocimiento lejos de pretender ser totalmente impersonal y objetivante. Después de la segunda mitad del siglo XX se superó la dedicación y prelación que la epistemología hacía en relación con los aspectos cognitivos y metodológicos de la ciencia, para luego enfocarse sobre el componente personal del conocimiento científico, abordando paradigmas de comprensión más amplios. Este giro epistemológico pretende abrirse a la consideración de que la ciencia es una actividad humana, que no descuida sus propios caminos metodológicos, pero sí se abre a caminos de carácter ético-antropológico y metafísico. Vitoria (2011) muestra como ejemplo a Stanley Jaki quien fue un sacerdote, físico e historiador de la ciencia, que en su tiempo afirmaba que la "ciencia y fe son dos modos de acercamiento, ambos racionales, con métodos distintos" (San Martin, 2011, p. 1). Jaki contribuyó con sus estudios históricos, ante todo, a la clarificación del origen cristiano de la ciencia moderna, en continuidad con lo que habían sostenido precedentemente otros historiadores de la ciencia como Pierre Duhem y Alexander Koyré, entre otros (Vitoria, 2011, p. 52). La autora rescata una idea muy valiosa: la misma ciencia en su quehacer ha ampliado su racionalidad, ella misma se ha encargado de mostrar la insuficiencia de la racionalidad del positivismo para dar cuenta de aspectos o realidades que no pueden ser objeto directo de observación y de medida, como son la teoría atómica o la composición química de las estrellas. De todo esto la misma ciencia se ha encargado de presentar resultados y así mismo se ha dado cuenta de
La imposibilidad de las ciencias naturales de responder satisfactoriamente a la cuestión más importante de todas, la pregunta por el significado último de la vida humana, queda en evidencia que el marco hermenéutico positivista resulta estrecho para responder al anhelo de explicación y de verdad de la inteligencia humana. Para el hombre, estas preguntas últimas no son opcionales: no se presentan como objeto de elección, sino que surgen como una exigencia intrínseca de la constitución racional y libre del ser humano. Son interrogantes universales e inevitables. Todo hombre tropieza con ellos en algún momento de su existencia y, aunque intente eliminarlos o silenciarlos, acaban presentándose [...]" (Vitoria, 2011, p. 54).

Es pertinente aquí ilustrar dos ejemplos de aperturas que intentan superar las limitaciones de la razón moderna para mostrar posibles caminos que permitan una apertura a otras razones, Vitora (2011) habla de dos autores que podrían ilustrar el hecho de que la ciencia puede abrirse a algo más allá de lo empírico o bien la filosofía puede desde la ciencia abrirse a otras racionalidades. Uno de los representantes del ateísmo filosófico es Anthony Flew ${ }^{4}$, quien en 2004 causó gran sorpresa al proclamar la existencia de Dios, en un Congreso en Nueva York, contradiciendo el inflexible ateísmo que había mantenido durante más de medio siglo. Su nueva postura se apoyaba en los descubrimientos científicos relacionados con el origen de la vida y la evolución

4 Anthony Flew, filósofo inglés (1923-2010), profesor en Oxford, Aberdeen y Toronto. Ha sido considerado por decenios uno de los principales exponentes del ateísmo filosófico (Vitoria, 2011). 
de los seres vivientes, y llegó a la conclusión de que, a pesar de numerosos intentos, estos hechos no pueden explicarse desde "un punto de vista simplemente biológico, naturalista y casual. El origen de las leyes de la naturaleza inanimada, de la vida $y$, en definitiva, del universo conducen claramente a una Fuente de su inteligibilidad"5 (Flew, 2007, citado por Vitoria, 2011, p. 10). Se registra entonces una apertura filosófica a la trascendencia desde la ciencia en el testimonio de Anthony Flew. Es claro que el filósofo no concluyó la identificación de la fuente de la inteligibilidad, pero al menos se mostró receptivo a esta posibilidad.

El segundo ejemplo es el argumento de Francis Collins ${ }^{6}$, que da cuenta de una apertura de la razón científica a la dimensión ético-religiosa. Para esto, parte de una posición agnóstica y luego atea, registrando que puede haber en la complejidad del orden que presentan la genética y la biología en general algo de un lenguaje que puede relacionarse con Dios, reconociendo a su vez que la ciencia no es una herramienta adecuada para conocer la existencia de Dios y dar respuestas a las cuestiones fundamentales de la existencia, pero puede proyectar al hombre más allá del conocimiento empírico. El científico asevera que

\section{Al confrontarse habitualmente con la asombrosa inteligibilidad de la na- turaleza puede alcanzar la percepción}

5 Flew, A. (2007). There is a God: How the world's most notorious atheist changed his mind. New York: Harper Collins.

6 Francis Collins (1950- ) genetista estadounidense de fama internacional. Es particularmente conocido por haber dirigido el Human Genoma Research Institut, la institución pública que en 2005 presentó la secuencia del genoma humano. Actualmente es director del Nacional Institute of Health (USA) (Vitoria, 2011). de una Razón como fundamento de la racionalidad de los dinamismos que él logra formular. La investigación científica que muchos ven como motivo para negar la existencia de Dios, se presenta, de suyo, como camino privilegiado para encontrarle (Collins, 2006 citado por Vitoria, 2011 p. 12).

Collins va un poco más allá y da dos saltos en el reconocimiento de la inteligibilidad de la naturaleza. El primero es que hay algo de reverencia ante la cual hay que mostrar humildad y sobrecogimiento en los hallazgos genómicos, y el segundo es la actitud ética que se debe expresar en la actividad científica no impuesta desde afuera, sino como una condición para hacer de la ciencia no un producto comercial sino un servicio.

Por lo anterior, Collins consideró que los resultados de la secuenciación del genoma humano no deberían ser patentados, sino puestos al servicio del bien común. Por ello, depositaba los resultados en bases de datos públicos.

Este es un claro ejemplo de un uso plural de la razón, que da muestras de un doble compromiso de la actividad científica: en el plano teórico al servicio de la verdad y en el plano práctico como instrumento para el servicio del bien para la humanidad (Vitoria, 2011, p. 59).

A esta altura de la discusión se puede vislumbrar la urgencia de ampliar la razón reconociendo su anhelo de verdad, lo que sí permite la relación con los diversos conocimientos con la razón última de vivir, los cuales podrían provenir desde los caminos que abre la ciencia misma, cuando hace reconocimiento de sus propios límites. 


\section{Contacto con la vida}

Para Schrödiger (1951) es importante que aquellos que desarrollen una disciplina mantengan el contacto con la vida, no solo con la vida práctica. Es decir, el sentido de lo que hace y para qué sirve el conocimiento científico se evidencia cuando se puede explicar a una gran mayoría de gente qué se está haciendo, pues la ciencia no solo sirve para inventar o ayudar a inventar nuevas y mejores máquinas o técnicas sociales, con el fin de optimizar las condiciones de vida. La ciencia tiene un trasfondo idealista en la vida humana, hace parte del legado cultural humano y de la cotidianidad del vivir (pocas veces percibido). Schrödiger menciona que aún en los tiempos modernos se produce un espejismo por el que se puede fácilmente caer en la falacia de la subestimación de la tarea idealista de la ciencia:

[...] en mi opinión el origen de este espejismo se sitúa hacia la segunda mitad del siglo XIX, período de un auge científico sin igual, en el que la industria y la ingeniería ejercieron tan marcada influencia en los aspectos materiales de la vida que la mayoría de las personas olvidó todas las demás relaciones. Pero lo que es peor es que el tremendo desarrollo material produjo una perspectiva materialista, supuestamente derivada de los nuevos descubrimientos científicos (Schrödinger, 1951, p. 20).

Lo que llama Schrödinger tarea idealista de la ciencia se interpreta como la relación ciencia-humanismo (relación que al deteriorarse creó las llamadas dos culturas anteriormente expuestas) fragmentada según él en el siglo XIX por el desarrollo industrial que hicieron de la ciencia una especie de "tonta útil" que debía producir el conocimiento estrictamente necesario para la prosperidad industrial. Esto tuvo como consecuencia un apogeo materialista, haciendo que el aporte de la ciencia a la humanidad "solo" se validara en términos de utilidad material (lo cual no es de menospreciar), pero dándole menos peso o validez por aquello que la ciencia pudiera preocuparse o aportar a la reflexión filosófica e histórica, tanto de su propio quehacer como de las condiciones donde se produce.

Por ello, el autor manifiesta que se presentó un deliberado descuido de la ciencia por parte de la gente; esto era de suponer, pues en la gente se empezó a gestar una especie de desdén por la profundidad de las cosas, por el conocer o preguntarse por el origen de las cosas: ¿para qué estudiar o mejor para qué pensar la o en la ciencia, si finalmente eso pertenece a unos especialistas y unos industriales que ya saben cuál es su tarea?, ¿para qué entregarnos un mayor y mejor progreso, prosperidad, comodidad, rapidez y tecnología?, para que "no tengamos que mover muchos músculos en el desplazamiento corporal", pero sobre todo para que no tengamos que pensar mucho.

Ya todo estaba, la prosperidad y el progreso nos los daba la ciencia, solo tenían que poner en marcha sus designios.

Al respecto, nos ilustra Einstein: “¿debemos estar preocupados por el hecho de que estamos viviendo una época de peligros y necesidades? Yo no lo creo. El hombre, como cualquier animal, es indolente por naturaleza. Si nada le motivara, apenas pensaría y terminaría comportándose como un 
autómata" (2007, p. 37). El científico se constituye en otra voz que promueve un pensamiento unificador, que trasciende más allá del mero quehacer científico y tecnológico:

[...] por encima de esta evaluación de nuestro tiempo, tenemos el deber de cuidar de lo que es eterno y de todo lo que está por encima de nuestras posesiones, de todo eso que le da a nuestra vida su importancia y que deseamos entregar a nuestros hijos de una manera más pura y rica que la nos dieron nuestros antepasados (p. 38).

¿Acaso se referirá Einstein a la felicidad o a un sentido superior, que supera el solo estudio de los fenómenos o hechos? Estas preguntas son parte de la tarea humana en busca de su sentido, tarea compartida por las tres culturas: humanidades, ciencias naturales y ciencias sociales.

\section{LÍMITES EN LA PROPIA DISCIPLINA}

En el informe de la Comisión Alemana de Reforma Universitaria, citada por Schrödiger (1951), a propósito del exceso de especialización en las universidades, se menciona que:

Todo enseñante de universidad técnica debería poseer las siguientes virtudes:

a) Asumir los límites de su propia disciplina. Hacer conscientes a los estudiantes de estos límites a través de su docencia y mostrarles que, más allá de ellos entran en juego fuerzas que no son estrictamente racionales, sino que provienen de la vida misma y de la sociedad b) Mostrar en cada disciplina cómo conduce ésta más allá de su campo limitado a perspectivas de por sí más amplias, etc (Schrödinger, 1951, p. 18).

Más adelante el autor hace universal estas premisas y las extiende extensivas para cualquier profesor de cualquier universidad, y aún de cualquier escuela, del mundo, formulando lo siguiente:

No perder nunca de vista el papel que desempeña la disciplina que se imparte dentro del gran espectáculo tragicómico de la vida humana; mantenerse en contacto con la vida - no tanto con la vida práctica, sino más bien con el trasfondo idealista de la vida, que aún mucho más importante. Mantener la vida en contacto contigo. Si a la larga no consigues explicar a la gente lo que has estado haciendo, el esfuerzo habrá sido inútil (Schrödinger, 1951, p. 19).

Sin embargo, aunque se mantiene con la reflexión anterior la idea fragmentaria de disciplinas, es una puerta que admite la comunicación con otras ya sea a través del diálogo o del reconocimiento de los límites que posibilitan una intersección de saberes, lo cual es denominado como el contacto con la vida, y se le puede también nombrar como la posibilidad de otras miradas y racionalidades.

\section{Otras posibles vías para SUPERAR LA FRAGMENTACIÓN ENTRE CIENCIA Y HUMANISMO EN LA UNIVERSIDAD}

Si bien haría falta volver a construir de nuevo la historia para recomponer los pedazos perdidos y poder unir todas las piezas 
separadas entre ciencia y humanismo, es posible postular algunas vías que intenten no una unificación completa (algo pretensioso), sino una reducción de la fragmentación de manera más viable, principalmente en la universidad, lugar de expresión máxima de dicha fractura, que obviamente se refleja en todas las demás esferas de la sociedad.

Dentro de estas aperturas a nuevas lógicas se encuentra el uso de la metáfora como un elemento necesario y fructífero:

\section{El mundo dejó de concebirse como un conjunto de hechos y pasó a mostrarse como textualidad. El mundo ya no era un objeto distante, sino algo que in- terpretar. Los científicos pasaron a ser lectores, intérpretes de un texto apasio- nante al que llamamos realidad. $Y$ esa realidad se configuraba, se construía, gracias a nuestros conocimientos pre- vios como lectores portadores de otros textos, gracias a nuestra enciclopedia de conocimientos (Aguirre, 2002, p. 7).}

La comprensión de la complejidad de la realidad se refleja en el concepto textual de dicha realidad, lo que hace necesario "abandonar los esquemas simplificadores de la realidad en beneficio de una concepción del mundo como sistema complejo" (Aguirre, 2002, p. 7) Según Aguirre (2002), "el universo, es un texto cuyos signos podemos captar, pero cuyo sentido tenemos que interpretar afinando poco a poco su significado, estableciendo hipótesis sobre su sentido y funcionamiento"(p. 7)

Esta noción del universo y del mundo, aunque metafórico, permite otro tipo de lógica con la que nos acercamos a él, tanto científicos como humanistas, pues nos permite asumir una postura de lectores ante la cual vamos "descubriendo páginas sucesivas" a las que les damos nuevos significados,. En este punto, por ejemplo, "la Ciencia encuentra un nuevo párrafo o un nuevo sentido parcial que obliga a revisar todo el texto, un párrafo descubrimiento que obliga a modificar el sentido de la totalidad del texto, produciéndose un cambio de paradigma" (Aguirre, 2002, p. 7). De esta manera, se puede concebir la ciencia como partícipe del entretejido que se denomina cultura.

Se trae a colación la anterior afirmación porque se rescata lo que Aguirre (2002) destaca respecto a que nada está aislado en la cultura:

[...] Como nada está aislado en el universo de la Ciencia: la Cultura como Sistema y el Universo como Sistema. Ambos, los reinos de la complejidad. La situación de la Ciencia respecto al mundo es, pues, hermenéutica. Como ante cualquier otro tipo de textualidad o situación de comprensión funciona el método del "círculo hermenéutico", un constante ir y venir entre los conocido y lo por conocer, porque lo nuevo solo se puede comprender desde lo que ya sabemos, desde la tradición, como una tensión, como una relación dialéctica (Aguirre, 2002, p. 8).

Si la situación de la ciencia es hermeneuta, entonces el parentesco con las humanidades es muy cercano, ya que nos enfrentamos a textos "cargados con otros textos y con nuestros conocimientos acumulados sobre ellos" (Aguirre, 2002, p. 8). En un intento colectivo de dar esclarecimientos tratando de 
juntar los elementos parciales con los que el conjunto se ve afectado. Sin embargo, aún la interpretación tiene sus límites y para bien, pues está abierta a otras interpretaciones que se actualizan y permanecen abiertas a futuras interpretaciones.

De esta manera, el uso de las metáforas ayudaría muchísimo para preservar lo que Aguirre (2002) llama un todo imbricado del sujeto humano ya que este "no puede prescindir de su dimensión humana, ni de su condición biológica ni de su condición sociocultural. Una y otra se imbrican formando un todo perceptivo" (p. 5). Para ilustrar mejor lo anterior, se muestra un ejemplo del biólogo Richard C. Lewontin ${ }^{7}$ (2000) (citado por Aguirre (2002):

No es posible ocuparse de ciencia sin utilizar un lenguaje rico en metáforas. En teoría, todo el cuerpo de la ciencia moderna es un intento de explicar fenómenos de los cuales los seres humanos tienen una experiencia directa, aunque hace referencia a fuerzas y procesos que no podemos percibir directamente porque son demasiado pequeños, como las moléculas, o demasiado grandes, como todo el universo conocido; o bien se refiere al resultado de las fuerzas que nuestros sentidos no pueden captar, como el electromagnetismo o incluso el resultado de interacciones extremadamente complejas, como el nacimiento de un organismo individual desde el momento en que queda concebido en forma de óvulo

7 Lewontin, R. C. (2000). Genes, organismos y ambiente. Las relaciones de causa y efecto en biología. Barcelona: Gedisa (citado por Aguirre, 2002). fecundado. Para que tales explicaciones no sean sólo proposiciones formales expresadas en un lenguaje técnico inventado, sino que están basadas en la comprensión del mundo que hemos logrado con nuestra experiencia cotidiana, debemos recurrir al empleo del lenguaje metafórico (Lewontin, 2000, citado por Aguirre, 2002, p. 6).

De igual manera, se requiere un nuevo humanismo que en concordancia con Aguirre (2002) demanda cambios profundos en su conceptualización; no únicamente como una invención o recreación cultural del pasado, sino comprometidos, además con los tiempos antiguos, con su propio tiempo en apertura a nuevas situaciones, a nuevos espacios que se presentan ante los hombres. “El autor prefiere considerar el Humanismo más como un impulso que como un depósito, más como una energía que como un cúmulo de conocimientos eruditos" (Aguirre, 2002 , p. 10). Dar respuestas vivas construidas a partir del legado, en síntesis, es lo que se exige de los nuevos humanismos.

\section{TRANSDISCIPLINARIEDAD Y DIÁLOGO DE SABERES}

Muchos científicos consideran que ha llegado el momento de hacer una síntesis integradora, de crear puentes entre las disciplinas que nos ayuden a componer una imagen más armónica de la naturaleza y del hombre como parte integrante de ella. Los aportes de Prigogine en esta búsqueda son fundamentales, tanto en su trabajo específico, que abre las puertas de la ciencia al estudio de la complejidad, como en su búsqueda de integración con otras disciplinas y su trabajo en pro de una nueva alianza y 
de un diálogo fecundo entre la ciencia y la filosofía (Najmanovich, 2005).

Por otro lado, existen colectivos de pensamiento crítico que dan cuenta de nuevas miradas y redifiniciones, tales como los aportes del grupo Modernidad colonialidad M/C, que plantearon durante la primera década del siglo XXI alternativas auténticas y aportes al pensamiento postcolonial, desde América Latina, y que aunque muchos de sus integrantes ya no comparten los mismos derroteros, sus planteamientos persisten en su valor. Entre ellos se encuentra la propuesta del filósofo Santiago Castro-Gómez en cuanto a Decolonizar la Universidad. (Castro-Gómez, 2007). Según el autor los nuevos paradigmas de la ciencia enunciados anteriormente, que se orientan al abandono de la linearidad por la opción de la complejidad, serían de mucho provecho para la universidad por cuanto "una universidad que piensa complejamente debe ser también una universidad que funciona complejamente" (Castro-Gómez, 2007, p. 87). El autor propone

Una universidad donde los estudiantes puedan ser coautores de sus propios planes de estudio, matriculándose, ya no en las estructuras fijas de un programa en particular, sino en una red de programas. El estudiante podría navegar, así, entre diversos programas de maestría e incluso de pregrado, conectados en red, no sólo en el interior de una sola universidad sino entre varias universidades. Pienso en una estructura donde los profesores puedan pertenecer a varios departamentos a la vez, facilitando así el ejercicio de la transdisciplinariedad [...] (Castro-Gómez, 2007, p. 87).
Otro planteamiento interesante y que podría permitir el dialogo de saberes sería pensar la universidad transcultural, que plantea el mismo autor. Para ello se hace necesario romper con las epistemes heredadas del siglo XVIII, de la ciencia occidental que estableció "que entre más lejos se coloque el observador de aquello que observa mayor será también la objetividad del conocimiento" (Castro-Gómez, 2007, p. 90). Esto por supuesto aleja los saberes de las otras culturas, tanto de las dominadas en la tradición colonial (Asia, África y América Latina, que entre los siglos XVI y XIX fueron sometidas al dominio colonial europeo), como las que quedaron en la actualidad: "La universidad debería entablar diálogos y prácticas articulatorias con aquellos conocimientos que fueron excluidos del mapa moderno de las epistemes por habérseles considerado "míticos", "orgánicos", "supersticiosos" y "preracionales" (Castro-Gómez, 2007, p. 90).

Es importante saber que no se trata de una cruzada contra Occidente, pretendiendo que entonces los saberes ancestrales y excluidos de la tradición sean ahora los valederos; por el contrario, se propone un verdadero diálogo:

De una ampliación del campo de visibilidad abierto por la ciencia occidental moderna, dado que ésta fue incapaz de abrirse a dominios prohibidos, como las emociones, la intimidad, el sentido común, los conocimientos ancestrales y la corporalidad. No es, entonces, la disyunción sino la conjunción epistémica lo que estamos pregonando. Un pensamiento integrativo en el que la ciencia occidental pueda "enlazarse" con otras formas de producción de conocimientos, con la esperanza de que 
la ciencia y la educación dejen de ser aliados del capitalismo postfordista (Castro-Gómez, 2007, p. 87).

En sintonía con estas ideas, a modo de ejemplo para finalizar este análisis sobre la fragmentación entre ciencia y humanismo, se presenta el siguiente caso cercano a nuestra realidad, donde se realiza una búsqueda seria en el interior de la disciplina de la biología, pero con aperturas a otras disciplinas que permitan un diálogo o bien un tejido epistemológico.

\section{Caso de ejercicio MULTIDISCIPLINAR}

A continuación presento un ejemplo en la búsqueda de aperturas a otras racionalidades, desde las ciencias naturales, como el caso del grupo Bioteórica del Departamento de Biología de la Universidad Nacional, como un impulso interno de romper con los límites disciplinares pero reconociéndolos a la vez.

“En sus planteamientos se proponen trabajar preguntas como: ¿Cuáles son las teorías que han construido a la Biología?, ¿Quiénes han generado dichas ideas integradoras?, ¿Cuál evidencia experimental apoya los diferentes paradigmas en Biología? Estas son algunas preguntas que el Grupo de Biología Teórica, 'Bioteórica'" (Universidad Nacional de Colombia, 2009, s.p.) ha abordado desde su creación en 2000, con el fin de generar un espacio de discusión multidisciplinario que permita construir una visión integral del fenómeno de la vida. Como parte del trabajo desarrollado por el grupo, en 2004 se publicó el libro Biólogos Lejos del Equilibrio. Nuevas metáforas evolutivas, resultado de un minucioso ejercicio de exploración y discusión de ideas relacionadas con evolución, en especial aquellas planteadas en el siglo XX. En 2005, el grupo organizó el debate "Interpretación de las teorías evolutivas en las ciencias de la vida en cuyo espacio se expusieron las principales corrientes del pensamiento que han participado en la construcción de teorías de evolución biológica. Es importante destacar que para llegar a sus resultados, el grupo ha transitado por campos diferentes a la biología, como son la filosofía, la psicología, la historia y la epistemología de las ciencias.

\section{Conclusiones}

Si bien el análisis no es fácil y tiene muchas aristas desde donde se puede analizar la fragmentación entre ciencia y humanismo dentro de la universidad contemporánea, se puede concluir que las fuerzas que actualmente conducen a la pronunciación de dicha fractura son tanto extrínsecas como intrínsecas a la universidad misma. Dentro de las primeras se encuentran los efectos globalizantes de una economía cada vez más deshumanizante, propiciadora del individualismo y de la anulación del saber por el saber, que obliga a la universidad a encuadrar a las ciencias y a las humanidades, para atender los intereses de los "patrocinadores" empresariales o industriales, instalando en ella una racionalidad puramente instrumental, alejándola de la academia articulada y del servicio a la sociedad a la cual se debe.

Dentro de las fuerzas intrínsecas se encuentran los obstáculos epistemológicos que se oponen a una visión orgánica de la realidad y de la vida, donde la división académica y administrativa interna de la universidad 
en disciplinas, Departamentos y Facultades plasma la idea de que la realidad debe ser dividida en trozos y de que el conocimiento valedero se logra solo mediante el examen o análisis de una de esas partes.

Pienso que las formas de recuperar la unidad se hallan en el interior de la universidad. La manera, que no es fácil, sería romper o bien empezar a desarticular las fuerzas intrínsecas que conducen a la fractura en dos o tres culturas, las vías propuestas son reconocer la necesidad de mirar la realidad con apertura a otras racionalidades, reconociendo la importancia del sujeto, y abandonar la pretensión de objetividad ante una realidad compleja.

La opción por una actuación educativa a nivel superior que transite en la transdisciplinariedad y en la transculturalidad sería de gran ayuda para encontrar la diversidad de respuestas que den cuenta de otras visiones alternas a las fragmentarias, visiones que propongan argumentaciones orgánicas de la realidad, con las que se podría hacer frente a las fuerzas extrínsecas que amenazan a la universidad con fracturarla más. Por ello se hace urgente mostrar resultados que presenten alternativas a los modelos de racionalidad homogeinizadores.

\section{ReFERENCIAS}

Aguirre, J. M. (2002). Ciencia, humanismo, humanidades y tecnología. III Encuentro Internacional sobre Literatura Española Contemporánea. Universidad Autónoma de México. Recuperado el 25 de marzo, de http://www.ucm.es/info/especulo/numero19/humanism.html
Bauman, Z. (2002). Modernidad Líquida. Buenos Aires: Fondo de Cultura Económica.

Castro-Gomez, S. y Grosfoguel, R. (2007). El giro decolonial: reflexiones para una diversidad epistémica más allá del capitalismo global. Bogotá: Siglo del Hombre, Universidad Central, Instituto de Estudios Sociales Contemporáneos y Pontificia Universidad Javeriana, Instituto Pensar. Cubides, F. (2006). Abrir las ciencias sociales. Unversidad Pedagógica Nacional. Recuperado el 5 de octubre de 2012, de http:// www.pedagogica.edu.co/storage/rce/ articulos/rce32_06contro.pdf

Delpech, B. (2011). Filosofar desde la realidad: repensar la ética después de la Segunda Guerra Mundial Fundacion Fraternitas. Congreso de Filosofía. Recuperado el 7 de octubre de 2012, de. http://www.academia. edu/4727824/Filosofar_desde_la_realidad_ repensar_la_etica_despues_de_la_Segunda_Guerra_Mundial._Levinas_y_ Adorno

Derrida, J.(1997). Las pupilas de la Universidad. El principio de razón y la idea de la Universidad Cómo no hablar y otros textos (en línea). Barcelona: Derrida en castellano. Recuperado el 16 de octubre de 2014 de http://www.jacquesderrida.com.ar/textos/universidad.htm

Einstein, A. (2007). Sobre el humanismo. Paidos. Heidegger, M. (2000). Carta sobre el Humanismo. Madrid: Alianza.

Herrera, D. (1986). Escritos sobre fenomenología Bogotá: Universidad Santo Tomás.

Horkheimer, M. (1973). Crítica a la razón instrumental. Buenos Aires: Editorial Sur Jaeger, W. (2001). Paideia, los ideales de la cultura griega. México: Fondo de Cultura Economica.

Lonergan, B. (2008). Conocimiento y aprendizaje. México, D.F: Universidad Iberoamericana . 
Lyotard, J.-F. (1990). La condición postmoderna, Informe sobre el saber. México: Rei.

Najmanovich, D. (2005). La Metamorfosis de la ciencia. Reflexiones sobre el pensamiento de Ilya Prigogine. Comunidad de pensamiento complejo. Recuperado el 20 de marzo de 2012, de http://www. pensamientocomplejo.com.ar/leerarticulo.asp?IdDocumento $=60$

Sanz Díaz, Carlos (2012) Tema 4. Europa en el siglo XIX. Revolución industrial y desarrollo capitalista. El ciclo liberal-revolucionario. Sistemas políticos y constitucionalismo. Sociedad burguesa versus movimiento obrero. Universidad Complutense de Madrid . Recuperado el 25 de marzo de 2012, de http://www.maec.es/ es/MenuPpal/Ministerio/EscuelaDiplomatica/MasterenDiplomaciayRelacionesInternacionales/Documents/EUROPAENELSIGLOXIX.pdf

San Martin, N. et al. (2011). Reconocer los límites del método científico, herencia del padre Jaki. Recuperado el 17 octubre de 2014, de http://www.zenit.org/es/articles/reconocer-los-limites-del-metodo-cientificoherencia-del-padre-jaki
Schrödinger, E. (1951). Ciencia y Humanismo. Barcelona: Tusquets.

Serrano, A. (2000). La filosofía ante los retos del siglo XXI. Algunas aproximaciones a un nuevo proyecto filosófico. Cuyo, Anuario de Filosofía Argentina y Americana, 17. Recuperado el 11 de octubre de 2012, de http://bdigital.uncu.edu.ar/objetos_digitales/1020/serranocuyo17.pdf

Snow, C. P. (1977). Las dos culturas y un segundo enfoque. Bogota: Alianza .

Universidad Nacional de Colombia (2009). Bio-UN noticias. Departamento de Biología. Recuperado de http://www.ciencias. unal.edu.co/unciencias/data-file/biologia/bioun/Bioun_7abril_2009.pdf

Vitoria, M. Á. (2011). Las aperturas de la razón científica. Del cierre positivista a la sensibilidad actual. Pensamiento y Cultura. Revista de Filosofía, 14(1), 49-62.

Wallerstein, I. (2006). Abrir las ciencias sociales (9na. edición) (volumen 50). Nueva York: Siglo XXI. 